\title{
Numerical Studies on a NACA0018 Airfoil Blade HAWT with Trailing Edge Jet Flow
}

\author{
Uzu-Kuei Hsu' ${ }^{1}$, Cheng-Hsien Tai ${ }^{2}$, Chia-Wei HSU${ }^{1}$ and Jiun-Jih Miau ${ }^{3}$ \\ ${ }^{1}$ Air Force Institute of Technology, No. 1, Jyulun Road, Gangshan Dist, Kaohsiung 82063, Taiwan. \\ ${ }^{2}$ National Pingtung University of Science and Technology, No.1, Shuefu Road, Neipu, Pingtung 91201, Taiwan. \\ ${ }^{3}$ National Cheng-Kung University, No.1, University Road, Tainan City 701, Taiwan
}

\begin{abstract}
This study analyzed an airfoil blade for a horizontal-axis wind turbine (HAWT) with a trailingedge jet flow design. This design was realized by drilling a hole in the trailing edge of an NACA0018 blade of a conventional HAWT to serve as a pressure injection nozzle. Five inflow wind speeds and three trailingedge jet flow conditions were examined in the test. The results revealed the efficiency differences between a HAWT with the new jet flow design and conventional HAWTs. The experimental methods employed involved a wind tunnel experiment and a computational fluid dynamics (CFD) simulation. The results revealed that when the inflow wind speed was low, the trailing-edge jet flow accelerated the initiation phase and increased the rotating speed of the HAWT; however, when the inflow wind speed was high, damping occurred and the rotating speed of the turbine blades decreased.
\end{abstract}

\section{Introduction}

Horizontal axis and vertical axis models constitute the two main types of wind turbine designs and can be distinguished by their appearances. Horizontal-axis wind turbines (HAWTs) can be divided into those with two blades, three blades, and over three blades. In real-world scenarios, turbines have either an upwind or downwind design. Currently, the most commonly employed design is the three-bladed HAWT. Designs of vertical-axis wind turbines (VAWTs) include Savonius rotor, Darrieus rotor, and $\mathrm{H}$ rotor models. Apart from the Savonius rotor, which rotates by drag force, the other rotors mentioned here operate by lift force [1], [2]. Numerous variations have been developed for HAWTs and VAWTs, and each variation exhibits strengths and weaknesses. For example, VAWTs require a higher startup wind speed and have low efficiency because their effective angle of attack varies considerably during each revolution. This impedes the design of an optimal blade shape [3]-[5]. However, HAWTs are not hampered by such limitations, and have become the main turbine design used worldwide. This is because following numerous improvements, they now approach the Betz limit. However, HAWT blades generate a considerable antitorque force during rotation, which leads to the requirement of additional reinforcements for the tower and base structure [6]. These requirements limit the flexibility regarding turbine location and usage. In addition, in case of strong winds, turbines usually have a cut-out speed design - typically at approximately 20-25 $\mathrm{m} / \mathrm{s}$ - to prevent the breakage of blades due to excessive rotation speed [7].
In 1891, La Cour installed the first experimental wind turbine to study the application of wind power. Currently, both HAWT and VAWT designs are limited to harnessing the relationship between the atmospheric boundary layer and the ground level [8], which causes inconsistencies regarding wind power in wind fields and poor power generation efficiency. Moreover, due to structural issues, turbines require substantial space for construction, thereby hindering their application. According to [9], recent wind power devices are based on a tower or pillar structure and involve high production costs. These tower or pillar structures have a height limit of $150 \mathrm{~m}$, and the height of such a structure cannot be adjusted according to the upper-air climate; therefore, both excessive and insufficient wind speeds compromise normal power generation mechanism.

The CP is close to 0.4 for a good-designed wind turbine. It is not only caused the structure failure of the wind turbine by the high wind speed, but also reduced the wind power transfer by the wind drag. The low efficiency bypass flow is induced by the reverse pressure because the wind flow is not easily through the wind power system. A kind of design, wind cup, was applied to deal with this problem, and it can increase the $\mathrm{CP}$ about $5 \sim 10 \%$. However, the problems still exist in "reverse pressure" and "cut speed" in high wind speed. This study is to develop a device which produces highpressure tailing jet. For the horizontal axis wind turbine, it can accelerate the rotation to increase power output in low speed, and produce a stable anti-torque force to wind turbine in high speed. It becomes the all day long operations, not only to overcome the problem of reversed pressure in high speed and cut off wind speed. 
It greatly enhances the $\mathrm{CP}$ value, and structure of the wind turbine is more robust and easy to control. It provides a new thinking for wind turbine design.

\section{Experimental apparatuses}

This experiment was conducted in the wind tunnel laboratory of the Air Force Institute of Technology. This wind tunnel used has a length of $11.68 \mathrm{~m}$, and is a lowspeed, open-circuit, and suction-type wind tunnel. The main structure can be divided into a settling chamber, a contraction section, a test section, and a drive section. In the rear of entry segment placed with honeycomb nest and layers of sieve, its main function is to adjust the speed of the flow field, to reduce speed disturbance form the side, and to eliminate large-scale vortex and turbulent flow. Contraction section is used to accelerate fluid velocity and reduce speed disturbance from upstream. Experiment wind measured from the test section inlet cross-sectional center resulting uniform flow of low turbulence which is less than $1 \%$ and maximum test speed can be up to $30 \mathrm{~m} / \mathrm{s}$. The test conditions are inflow speed and mass flow of the jet flow. There are nine kinds of inflow speeds $(2 \sim 10 \mathrm{~m} / \mathrm{s})$ and three kinds of trailing edge jet flow $\left(0.5,1.0\right.$, and $\left.1.5 \mathrm{kgf} / \mathrm{cm}^{2}\right)$ in analysis. The wind tunnel setup and test model are shown in Fig. 1. The setup of the wind tunnel is as follows:

\subsection{Settling Chamber}

The settling chamber $(130.8 \mathrm{~cm}$ long $\times 289 \mathrm{~cm}$ wide $\times$ $211 \mathrm{~cm}$ tall) at the entrance of the wind tunnel is a flowstraightening device containing a honeycomb and screens. The honeycomb acts as a filter that break up eddies from the downstream of the honeycomb into smaller eddies to reduce the static turbulence and cross turbulence of the airflow, which minimizes turbulent force in the flow field and increases the uniformity and stability of the airflow; in addition, this renders the separation of the boundary layer in the contraction section less likely to occur.

\subsection{Contraction Section}

This is the most crucial section for airflow straightening. Its main function is to further suppress the turbulence in the airflow that passes through the preceding flow straightener. This section is responsible for steady flow approximation in the test section; therefore, it requires special consideration.

\subsection{Test Section}

In this wind tunnel, this section is $215 \mathrm{~cm}$ long, $100 \mathrm{~cm}$ wide, and $65 \mathrm{~cm}$ tall. This section comprises fixed steel panels on the top and bottom and large transparent movable acrylic sheets on both sides, which enables users to directly observe wind tunnel flow.

\subsection{Drive Section}

This section comprises a contraction tube, fan, and diffuser. The contraction tube has a rectangular entrance that gradually shrinks into a round fan opening with a $1.3 \mathrm{~m}$ diameter. Because eddies generated by fan movement in a blowing-type wind tunnel may affect the uniformity and stability of airflow in the test section, the wind tunnel used in this study has a suction-type fan. The fan has a diameter of $1.3 \mathrm{~m}$ and contains ten fan blades. To prevent the vibration caused by motor and fan blade rotations affecting the experimental results, the drive section and the test section were connected by a piece of soft canvas; in addition, the drive section has a standalone foundation to prevent vibration transmission.

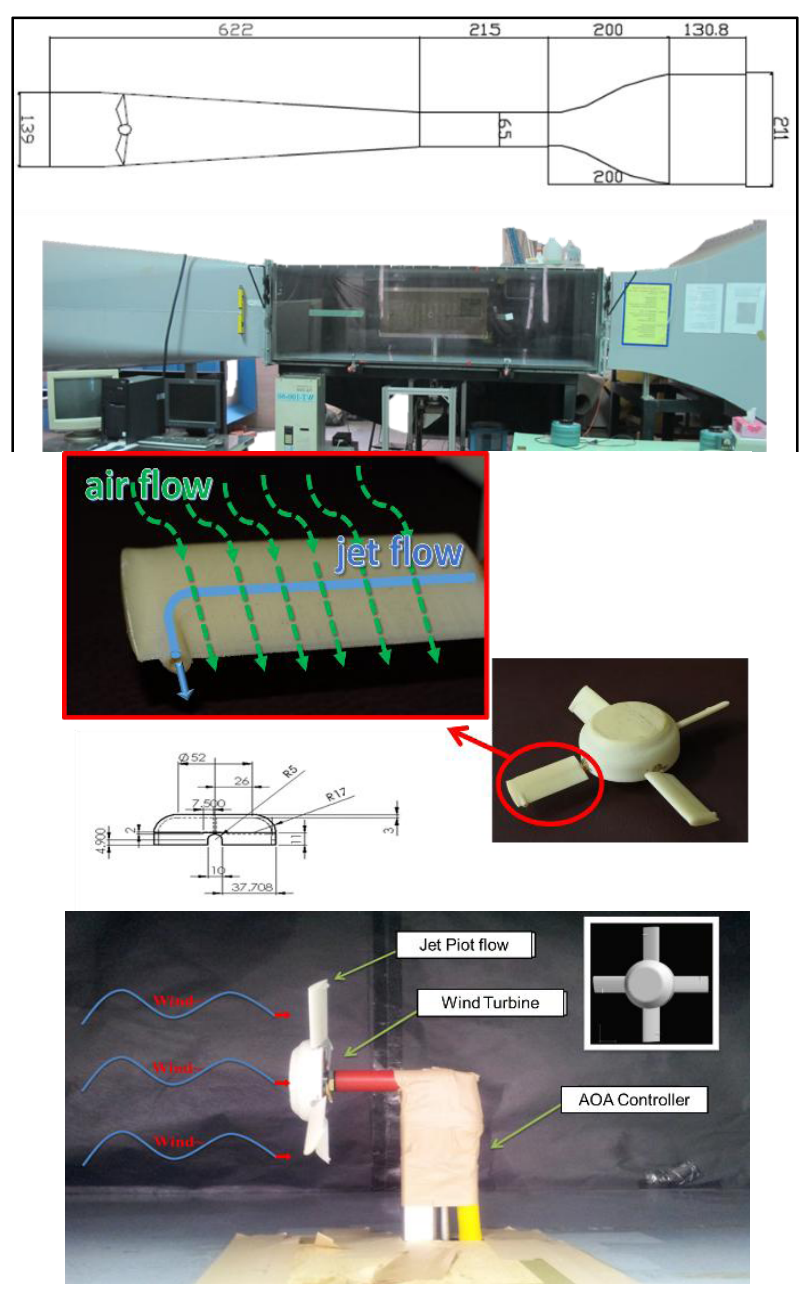

Fig. 1. Wind tunnel and test model.

\section{Numerical method}

\subsection{Governing equations}

This study computes the unsteady viscous flow-fields by solving the Reynolds-averaged Navier-Stokes equation (1) combined with the continuity equation (2), as follows.

$\frac{\partial}{\partial t}\left(\rho u_{i}\right)+\frac{\partial}{\partial x_{j}}\left(\rho u_{i} u_{j}\right)=-\frac{\partial p}{\partial x_{i}}+\frac{\partial \tau_{i j}}{\partial x_{j}}+\rho g_{i}$ 


$$
\frac{\partial \rho}{\partial t}+\frac{\partial}{\partial x_{i}}\left(\rho u_{i}\right)=0
$$

The simulations are performed using the CFD scheme on the control-volume method. The aerodynamic characteristics for passing of the rotational wind turbine are associated with the dynamic unsteady flow field. This study will focus on the transient aerodynamic coefficient effects caused by the different rotating speeds and different inflow speeds. The flowfield is assumed to be turbulent and the conservative variables are solved sequentially. The terms representing convective and diffusive flux are evaluated using the second-order accuracy hybrid differential scheme. In addition, the coupling between the pressure and the velocity is achieved by means of the SIMPLE algorithm [10], while the time accuracy is improved by performing the FAS multi-grid method. The residual smoothing approach is also applied to accelerate the convergence of solutions within each physical time step, and the sliding mesh technique in dynamic mesh is used to analyze the different cases. Two hexahedron mesh blocks are established before starting the transient iterations. First of all, the sliding and non-sliding blocks are defined before setting up the interface zone that varies when the blocks move. During the iterations, the solver will interpolate the variables on the overlapping surface at both sides.

\subsection{Turbulence Model}

Because there are two air-conditioners operating inside the cabin, the flow field belongs to the turbulent status. In order to simulate the turbulence status inside a closed space, it will require a certain degree of preciseness for near-wall flow field simulation. So, in this research, we adopt RNG $\mathrm{k}-\varepsilon$ Turbulence Model to simulate the turbulent flow field induced by Reynold Stress terms in the momentum equation [11].

\section{Physical model and boundary conditions}

\subsection{Physical model}

The production of Grid System Calculating is the priority job in the application of hydrodynamics calculation. In this wind turbine case, ICEM/CFD software package is used to complete the physical model drawing and the fabrication of a 3-D structural hexahedron grid system. On the grid deployment, in order to effectively simulate the special phenomenon of the flow field, such as the encryption processing done in the area of wind blade and jet flow nozzle, one needs also to consider the matching between the grid spacing density and the aspect ratio tuning. Therefore, the grid system has been divided into 15 blocks with 2,218,759 grids. The calculation platform is a Lenovo P900 with a 2.4GHZ Xeon CPU E5-2630 (32 cores) and 64GB RAM.

\subsection{Boundary conditions}

Fig. 2 shows the computational domain. The boundary conditions are as following:

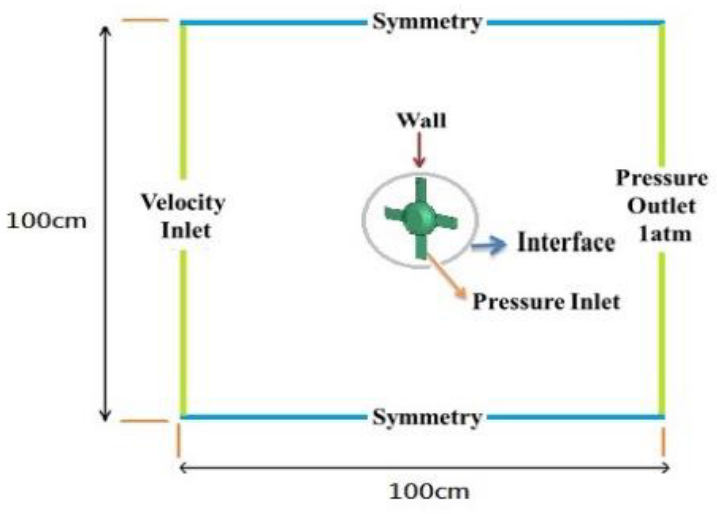

Fig. 2. Boundary conditions and computational domain in a NACA0018 Airfoil Blade HAWT (sliding grid in the interface, fixed grid out of the interface)

\subsubsection{Velocity Inlet}

The wind turbine usually reaches the rated capacity at a wind speed of between 10 to $16 \mathrm{~m} / \mathrm{s}$, depending on the design of the individual turbine. The cut-out wind speed is when the turbine stops production and turns out of the main wind direction. Typically, the cutout wind speed is in the range of 20 to $25 \mathrm{~m} / \mathrm{s}$. A typical starting wind speed for HAWT is about $2 \sim 7 \mathrm{~m} / \mathrm{s}$. In this study, there are nine wind speeds are used: $2 \sim 10 \mathrm{~m} / \mathrm{s}$ as shown in table 1.

\subsubsection{Outflow}

Assume a fully developed in the outlet, upper, and lower boundaries, because the pressure and velocity are unknown. In addition, consider the conservation, to make the mass flux out equal to the mass flux coming into the domain all the outlet velocity components ui,j are multiplied by the ratio $M_{\text {in }} / M_{\text {out }}$. Thus the outlet plane velocities with the continuity correction are given by

$$
u_{i, j}=u_{i-1, j} \times \frac{M_{\text {in }}}{M_{\text {out }}}
$$

\subsubsection{Wall}

In viscous fluid flow, the wall condition satisfies the noslip condition.

\subsubsection{Moving wall:}

The rotating part is set according to the wind turbine working principle. The boundary of the simulated surface is the interface of the HAWT, and the boundary condition adjacent to the wind turbine is set as the sliding interface to generate a sliding grid system. 


\subsubsection{Mass flow of the trailing edge jet:}

The jet flow on of the trailing edge on the wind blade has three cases to test: $0.5,1.0$, and $1.5^{\mathrm{kgf}} / \mathrm{cm}^{2}$

\section{Results and discussion}

Fig. 3 and Table 1 show the experimental results for rotation speed distribution trends under different inflow wind speeds and trailing-edge jet flow settings. When the inflow wind speed was set at $2 \mathrm{~m} / \mathrm{s}$ and trailing-edge jet flow was not applied, the blades were unable to overcome the static friction force; therefore, they did not rotate. However, with the introduction of trailing-edge jet flow, the blades started to rotate, and the rotation speed increased proportionally with the trailing-edge jet flow. Fig. 4 (a) and 4 (b) show the pressure distribution under an inflow wind speed of $2 \mathrm{~m} / \mathrm{s}$. When the trailingedge jet flow was weak, higher pressure was noted at the front of the blades. By contrast, when the trailing-edge jet flow increased, the high-pressure zone decreased. The velocity vectors in Fig. 5 show that the trailing-edge jet flow enabled the rotor to form a high-velocity trailingedge flow. This expanded the low-pressure zone at the back of the flow field and produced a suction affect at the front, which lowered the pressure in the highpressure zone and increased the flow speed through the turbine, thereby increasing the rotation speed.

Table 1. Studies matrix and experimental results.

\begin{tabular}{|c|c|c|c|c|c|c|c|c|c|c|}
\hline $\begin{array}{c}\text { Inlet } \\
\text { Velocity } \\
(\mathbf{m} / \mathbf{s})\end{array}$ & 2 & 3 & 4 & 5 & 6 & 7 & 8 & 9 & 10 & \\
\hline $\begin{array}{c}P_{\text {jet flow }} \\
0.0 \text { kgficm }\end{array}$ & 0 & 0 & 914.15 & 1089.5 & 1369.5 & 1584.63 & 1672.75 & 2289.75 & 2535.88 & \\
\hline $\begin{array}{c}P_{\text {jet flow }} \\
0.5 \mathrm{~kg} \mathrm{~kg}^{\prime} \mathrm{cm}^{2}\end{array}$ & 374.75 & 381.50 & 1047.75 & 1142.13 & 1435.38 & 1578.63 & 1648.38 & 1787,00 & 2518.88 & \\
\hline $\begin{array}{c}P_{\text {jet flow }} \\
1.0 \mathrm{kgl}^{f} \mathrm{~cm}^{2}\end{array}$ & 485.38 & 468.63 & 1032.25 & 1111.75 & 1366.75 & 1525.13 & 1609.50 & 1676.38 & 2452.00 & RPM \\
\hline $\begin{array}{c}P_{\text {jet flow }} \\
1.5 \mathrm{~kg} \mathrm{fl}^{2} \mathrm{~cm}^{2}\end{array}$ & 630.00 & \begin{tabular}{|l|}
727.88 \\
\end{tabular} & 1015.75 & 1078.25 & 1340.00 & 1485.13 & 1586.75 & 1635.38 & 2183.63 & \\
\hline
\end{tabular}

When the flow rate at the inflow wind speed increased to $5 \mathrm{~m} / \mathrm{s}$, the trailing-edge jet flow did not have a marked effect on the rotation speed and the pressure distribution, as shown in Fig. 3 and Fig. 4 (c)-(e). The maximal rotation speed occurred when the trailing-edge jet flow was set at $0.5 \mathrm{kgf} / \mathrm{cm}^{2}$. Increasing the trailingedge jet flow beyond this point resulted in a lower rotation speed; similar results were observed in the experimental conditions with inflow wind speeds of 4,5 , and $6 \mathrm{~m} / \mathrm{s}$. Fig. 6 reveals that when the trailing-edge jet flow was set at $1.5 \mathrm{kgf} / \mathrm{cm}^{2}$, a reverse eddy current formed at the back of the flow field and created a drag force in the upstream inflow. The aforementioned phenomenon can be further observed in Fig. 7; when the inflow wind speed was $10 \mathrm{~m} / \mathrm{s}$ and the trailing-edge jet flow was set at $1.5 \mathrm{kgf} / \mathrm{cm}^{2}$, the strong reverse eddy current collided with the inflow airflow, which decreased the rotation speed of the turbine blades. Moreover, as can be observed in Fig. 3 and Table 1, when the inflow wind speed was $10 \mathrm{~m} / \mathrm{s}$, the trailing-edge jet flow reduced the rotation speed, suggesting an inversely proportional relationship.

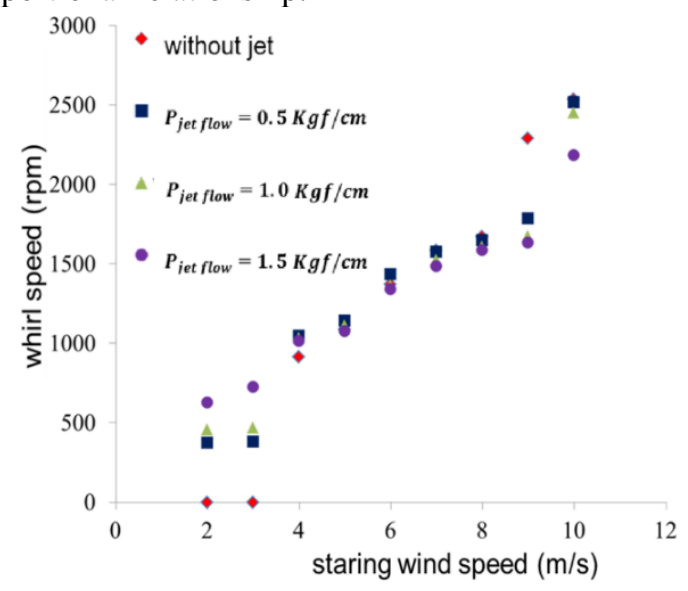

Fig. 3. Experimental results of the NACA0018 Airfoil Blade HAWT in different inflow and trailing edge jet flow.

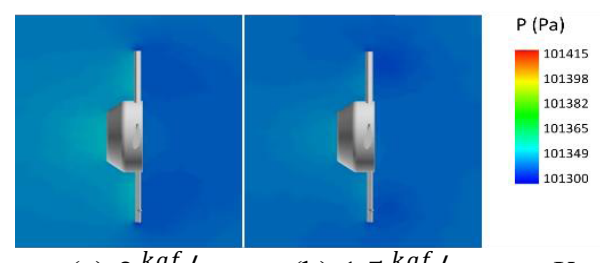

$\begin{array}{ll}\text { (a) } 0{ }^{\mathrm{kgf}} / \mathrm{cm}^{2} & \text { (b) } 1.5^{\mathrm{kgf}} / \mathrm{cm}^{2} \quad V_{\text {in }}=2 \mathrm{~m} / \mathrm{s}\end{array}$
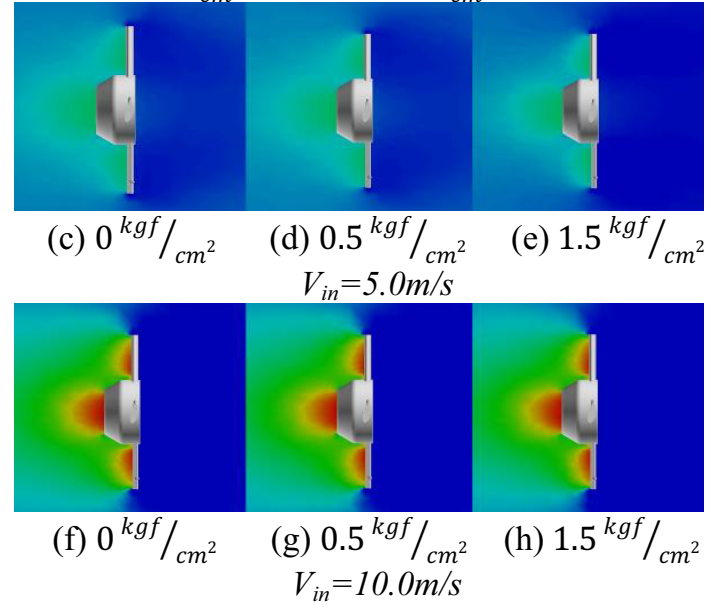

Fig. 4. Pressure distribution in Blade HAWT in different inflow and trailing edge jet flow

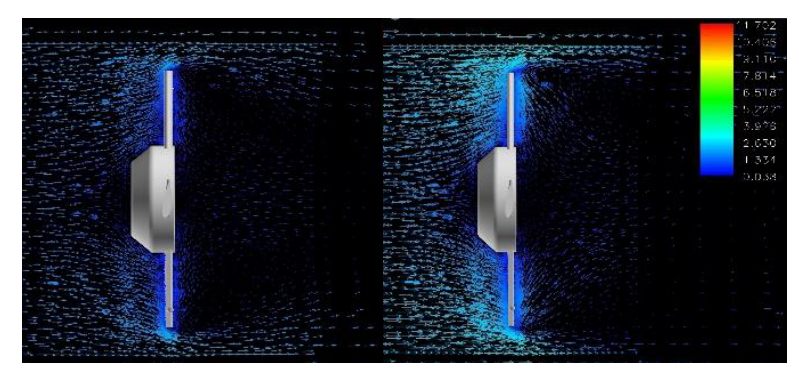

Fig. 5. Velocity vectors in Pressure distribution in $V_{\text {in }}=2 \mathrm{~m} / \mathrm{s}$ $\left(L: V_{\text {jet }}=0^{\mathrm{kgf}} / \mathrm{cm}, R: V_{\text {jet }}=1.5^{\mathrm{kgf}} / \mathrm{cm}\right)$ 


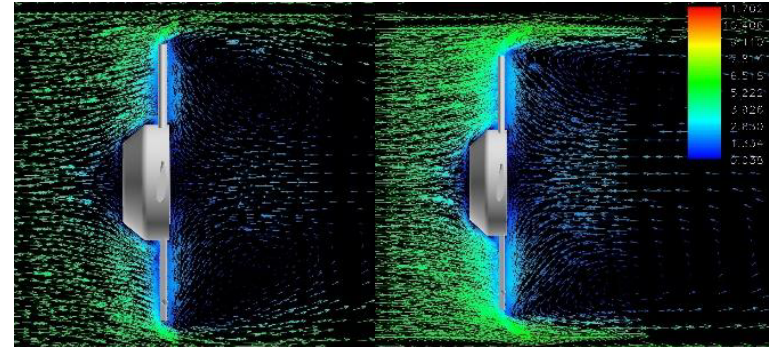

Fig. 6. Velocity vectors in Pressure distribution in $V_{\text {in }}=5 \mathrm{~m} / \mathrm{s}$ $\left(L: V_{\text {jet }}=0 \mathrm{kgf} / \mathrm{cm}, R: V_{\text {jet }}=1.5^{\mathrm{kgf}} / \mathrm{cm}\right)$

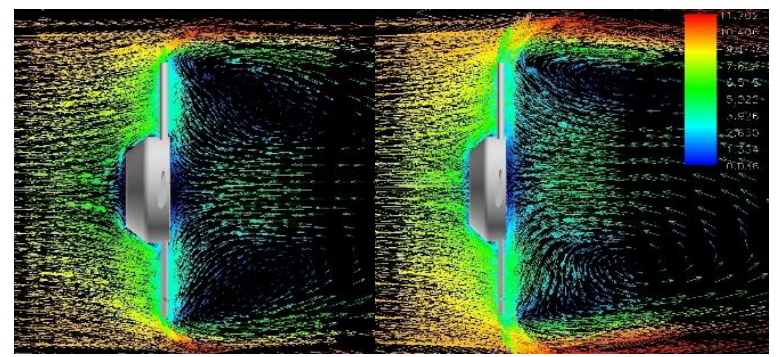

Fig. 7. Velocity vectors in Pressure distribution in $V_{\text {in }}=10 \mathrm{~m} / \mathrm{s}$

$$
\left(L: V_{\text {jet }}=0^{\mathrm{kgf}} / \mathrm{cm}, R: V_{\text {jet }}=1.5^{\mathrm{kgf}} / \mathrm{cm}\right)
$$

The experimental and simulation results demonstrated that in general, turbine blades rotated due to inflow and formed a partial high-pressure zone at the front of the turbine. When trailing-edge jet flow was applied, the flow velocity at the back of the turbine increased thus reducing the regional pressure. Additionally, the relative pressure difference caused a suction effect that increased the rotation speed of the turbine. However, as the inflow wind speed increased, the airflow passing through the turbine blades also sped up, and the blades rotating at a high speed caused shielding, which impeded the trailing-edge jet flow from moving downstream. Subsequently, as the eddy system developed, a strong inverse eddy current was established that blocked the upstream airflow and reduced the rotation speed of the turbine; as a result, a natural damping effect was observed.

\section{Conclusions}

In this study, a HAWT was developed with a trailingedge jet flow design. The experimental and simulation results revealed that with a low inflow wind speed, this design could assist in accelerating the turbine startup or and power output thereby overcoming the shortcomings of an HAWT. With a high inflow wind speed, this design caused a damping effect, which lowered the rotation speed and stabilized the turbine. These characteristics will allow this type of HAWT to operate efficiently under all weather conditions.

\section{Acknowledgement}

The author is grateful to the Ministry of Science and Technology of the Republic of China (Taiwan) for financial support under contract number MOST 1073113-E-006 -011.

\section{References}

1. Savonius SJ, "The S-Rotor and Its Application," Mechanical Engineering, Vol.53, No.5, pp.333-338, 1931.

2. Tony Burton, David Sharpe, Nick Jenkins, Ervin Bossanyi: Wind Energy Handbook, 2005.

3. Hayashi T, Li Y, and HARA Y, "Wind Turnel Test on a Different Phase Three-Stage Savonius Rotor," JSME International Journal, Series B, Vol.48, No.1, pp.9-16, 2005

4. Fujisawa N and Shibuya S, "Observations of dynamic stall on Darrieus wind turbine blades," Journal of Wind Engineering and Industrial Aerodynamics, Vol.89, PP.201-214, 2001

5. Hsu UK, Tai CH, Lin JY, "Dynamic Simulation of a Vertical Axis Wind Turbine with NACA4412 Airfoil," Journal of Aeronautics/Astronautics and Aviation, Series B, Vol. 41, No. 1, pp. 11-16, 2009.

6. Cristina L. Archer ,Ken Caldeira, "Global Assessment of High-Altitude Wind Power ," Energies, 2(2), 307-319; doi:10.3390/en20200307, 2009.

7. Paraschivoiu, I., Wind Turbine Design, Polytechnic International Press, 2002.

8. Burton T, Sharpe D, Jenkins N, and Bossanyi E, "Wind Energy Hand Book,” John Wiley and Sons, 2001.

9. Thresher R, Robinson M, and Veers P, "To capture the wind,” IEEE Power Energy Mag., vol. 5, no. 6, pp. 34-46, 2007

10. Patankar, S. V. (1980). Numerical Heat Transfer and Fluid Flow. Taylor \& Francis. ISBN 978-0-89116-522-4.

11. Yakhot, V. and Orszag, S. A., "Renormalization Group Analysis of Turbulence: I. Basic Theory," Journal of Scientific Computing, Vol. 1, pp. 1-51, 1986. 